\title{
Systematic Review on the Epidemiology and Management of the Dry Eye Disease in Sub-Saharan Francophone Africa
}

\author{
Rodrigue Romuald Elien Gagnan Yan-zaou-tou1,2* (D, Guirou Nouhoum1, Bakayoko Seydou1, \\ Dicko Mahamat Adam 1,3, Sissoko Modibo1, Sidibé Mohamed Kolé1, Mbaïkoua Jean Michel2, \\ Mananu Innocent Adubango1,4, Hann T. Fadimé1,5, Sylla Aly1,6, Diabaté Nagnan Cheick Rahim, \\ Diarra Modibo ${ }^{1}$
}

\author{
${ }^{1}$ Institute of Tropical Ophthalmology of Africa-Teaching Hospital (CHU-IOTA), Bamako, Mali \\ ${ }^{2}$ National University Hospital Center of Bangui-Teaching Hospital (CNHUB), Bangui, Central African Republic \\ ${ }^{3}$ National Reference-Teaching Hospital (CHU-RN), N'Djamena, Republic of Chad \\ ${ }^{4}$ Evangelical Medical Center of Nyankunde-Bunia, Bunia, Democratic Republic of Congo \\ ${ }^{5}$ Donka University Hospital Center, Donka, Republic of Guinea \\ ${ }^{6}$ Medical and Surgical Center of the Army, Conackry, Conakry Republic of Guinea \\ Email: ^rodrigueelien@yahoo.fr
}

How to cite this paper: Elien Gagnan Yan-zaou-tou, R.R., Nouhoum, G., Seydou, B., Adam, D.M., Modibo, S., Kolé, S.M., Michel, M.J., Adubango, M.I., Fadimé, H.T., Aly, S., Rahim, D.N.C. and Modibo D. (2020) Systematic Review on the Epidemiology and Management of the Dry Eye Disease in Sub-Saharan Francophone Africa. Open Journal of Ophthalmology, 10, 323-331.

https://doi.org/10.4236/ojoph.2020.104035

Received: September 10, 2020

Accepted: November 9, 2020

Published: November 12, 2020

Copyright $\odot 2020$ by author(s) and Scientific Research Publishing Inc. This work is licensed under the Creative Commons Attribution International License (CC BY 4.0).

http://creativecommons.org/licenses/by/4.0/

\begin{abstract}
Introduction: Dry Eye Disease (DED) is a multifactorial affection of the tears and the ocular surface. Its prevalence in the world varies between $7 \%$ and $33 \%$. To the best of our knowledge, the prevalence of DED in Subsaharan Francophone African countries is not yet known. The objectives of this systematic review were to determine the prevalence of DED, to identify the main risk factors for DED, and to determine the diagnostic and therapeutic management of DED in Subsaharan Francophone African countries. Methodology: This is a systematic review of articles, dealing with DED, published in English or French language from 2010 to 2020. The following key words (Prevalence OR Incidence OR Proportion OR Rate OR Frequency OR Epidemiology OR Distribution) AND (Risk Factors OR Influences) AND (Symptoms or Questionnaire) AND (Clinical Signs OR Clinical Tests) AND (Dry Eye Disease OR Dry Eye Syndrome) AND (Pharmacological Treatment OR Non-pharmacological Treatment OR Management) AND (Benin OR Burkina Faso OR Burundi OR Cameroon OR Cap-Green OR Central African Republic OR Congo OR Congo (Democratic Republic of) OR Ivory Coast OR Gabon OR Guinea OR Guinea-Bissau OR Equatorial Guinea OR Mali OR Madagascar OR Mauritius (island) OR Niger OR Rwanda OR Sao Tome and Principe OR Senegal OR Seychelles OR Chad OR Togo) in French and English were searched on Pubmed, Chocrane database, Google scholar and
\end{abstract}


ICTRP. Articles in English and French were selected from 2010 to 2020. Results: We selected 05 articles on the epidemiology and management of DED in sub-Saharan francophone Africa. The prevalence of DED in sub-Saharan francophone Africa in the articles ranged from 7.5\% to $90.4 \%$. DED affects more women than men. The risk factors found were: age over 50 years, diabetes, meibomian gland dysfunction, prolonged use of computers, and glaucomatous anti-glaucoma drugs. The Test of Breack Up Time (TBUT) was commonly used for the clinical diagnosis of dry eye disease in Sub-Saharan Francophone Africa. The therapeutic strategy for DED was not mentioned in any article. Conclusion: DED, a multifactorial and blinding eye disease, is insufficiently explored by eye health professionals in sub-Saharan Francophone Africa. The implementation of a systematic screening program and strategies for the treatment of dry eye disease in at-risk individuals would be beneficial for sub-Saharan Francophone African countries.

\section{Keywords}

Dry Eye Disease (DED), Epidemiology, Diagnosis, Treatment, Sub-Saharan Francophone Africa

\section{Introduction}

The Dry Eye Workshop Study (DEWS) in 2017 [1], defines DED as a multifactorial tear and eye surface disease characterized by the loss of tear film homeostasis and accompanied by ocular symptoms in which tear film instability and hyperosmolarity, inflammation and damage to the ocular surface and neurosensory abnormalities play etiological roles.

Worldwide, the prevalence of DED ranged from $7 \%$ to $33 \%$ [2] [3].

To the best of our knowledge, very few studies related to DED have been conducted in French-speaking sub-Saharan Africa [4] [5] [6] [7] [8]. Therefore, we feel it is necessary to make our contribution to the study of ocular dryness in French-speaking Sub-Saharan Africa. The objective of this first systematic review is to study the prevalence, risk factors, diagnosis and treatment of dry eye disease in French-speaking Sub-Saharan Africa.

\section{Methodology}

\subsection{Strategy of Research}

In our study, we used the Boolean operator (OR/AND) to search for all previously selected keywords. The Boorlean operator OR permits the link between keywords of the same thematic sub-group for example: (Prevalence OR Incidence OR Proportion OR Rate OR Frequency OR Epidemiology OR Distribution). The Boorleean operator AND permits to link two keywords flat to the different thematic subgroups for example: (Prevalence OR Incidence OR Proportion OR Rate OR Frequency OR Epidemiology OR Distribution) AND (Risk 
Factors OR Influences) AND (Symptoms or Questionnaire) AND (Clinical Signs OR Clinical Tests) AND (Dry Eye Disease OR Xerophtalmia OR Keratoconjonctivitis sicca) AND (Pharmacological Treatment OR Non-pharmacological Treatment OR Management) AND (Benin OR Burkina Faso OR Burundi OR Cameroon OR Cap-Green OR Central African OR Congo OR Congo (Democratic Republic of) OR Ivory Coast OR Gabon OR Guinea OR Guinea-Bissau OR Equatorial Guinea OR Mali OR Madagascar OR Mauritius (island) OR Niger OR Rwanda OR Sao Tome and Principe OR Senegal OR Seychelles OR Chad OR Togo) in French and English were searched on 04 search engines: Pubmed, Chocrane database, Google scholar and ICTRP.

We adopted a sensitive search strategy by making use of at least four search engines and with adapted search terms to find publications related to DED in French-speaking Black African populations. For each of the searches performed, dry eye or one of its synonyms such as "dry eye disease" and "keratoconjunctivitis sicca (KCS)" were used. We also included the names of each of the 23 countries of French-speaking Sub-Saharan Africa in each of the search text used; for example: "prevalence of dry eye disease in Central Africa". The citations, full text articles and abstracts were exported to the bibliographic software Zotero to sort the articles and eliminate duplicates. (See Figure 1, Figure 2)

\begin{tabular}{|c|c|c|c|c|}
\hline $\begin{array}{c}\text { Prevalence, OR } \\
\text { Incidence, OR } \\
\text { Proportion, OR } \\
\text { Rate, OR } \\
\text { Frequency, OR } \\
\text { Epidemiology, OR } \\
\text { Distribution, OR } \\
\text { Risk factors, OR } \\
\text { Influences, OR } \\
\text { Symptoms, OR } \\
\text { Questionnaire, OR } \\
\text { Clinical signs, OR } \\
\text { Clinical tests, OR } \\
\text { Pharmacological } \\
\text { treatment, OR } \\
\text { Non-pharmacological } \\
\text { treatment, OR } \\
\text { Management, OR }\end{array}$ & AND & \begin{tabular}{|} 
Dry Eye Disease \\
OR \\
Xerophtalmia \\
OR \\
$\begin{array}{c}\text { Eratoconjonctivitis } \\
\text { de sicca }\end{array}$
\end{tabular} & AND & $\begin{array}{c}\text { Benin OR } \\
\text { Burkina Faso OR } \\
\text { Burundi OR } \\
\text { Cameroon OR } \\
\text { Cape Verde OR } \\
\text { Central African } \\
\text { Republic OR } \\
\text { Congo OR } \\
\text { Congo (Democratic } \\
\text { Republic of the) OR } \\
\text { Ivory Coast OR } \\
\text { Gabon OR } \\
\text { Guinea OR } \\
\text { Guinea-Bissau OR } \\
\text { Equatorial Guinea OR } \\
\text { Mali OR } \\
\text { Madagascar OR } \\
\text { Mauritius (island) OR } \\
\text { Niger OR } \\
\text { Rwanda OR } \\
\text { Sao Tome and } \\
\text { Principe OR } \\
\text { Senegal OR } \\
\text { Seychelles OR } \\
\text { Chad OR } \\
\text { Togo }\end{array}$ \\
\hline
\end{tabular}

Figure 1. Search mode: main keywords. 
Potentially relevant articles identified

Pubmed: 12

Google scholar: 3

Cochrane database: 0

ICTRP www.who.int/ictrp/fr: 0

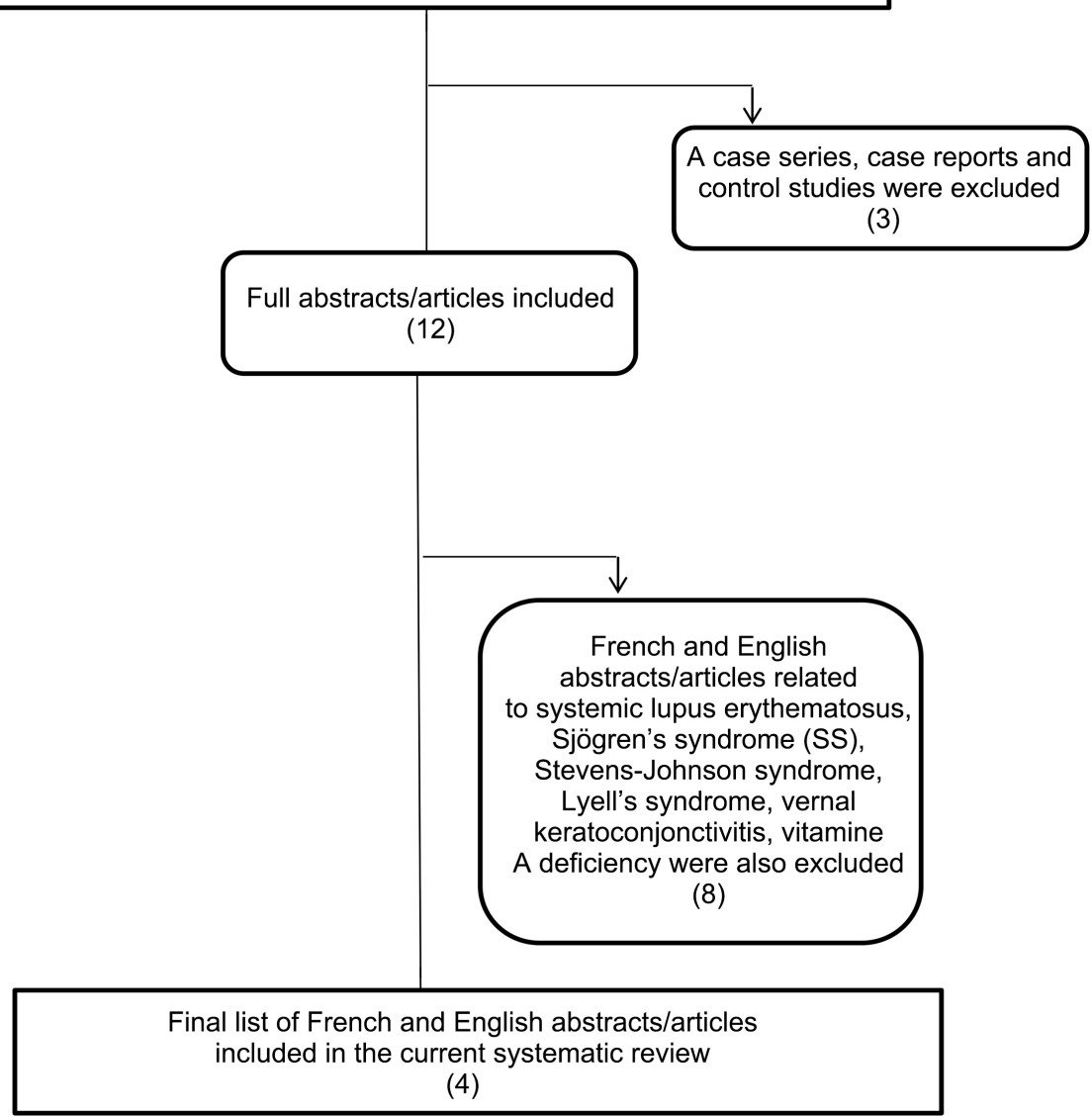

Figure 2. Flowchart of the current systematic review.

\subsection{Inclusion and Exclusion Criteria}

Studies could be included if they:

1) were published in English or French.

2) were conducted in French-speaking Black Africa.

3 ) involved only human subjects.

4) had at least some impact on the epidemiology of DED, in terms of etiology, risk factors, diagnosis, treatment, prevalence rates and distribution in Frenchspeaking Black Africa.

5) had a clearly defined study design and/or type of study.

6) contained some information on the objective and subjective clinical evaluation of the DED. (Since there is no reference test for the DED, we considered studies that reported a general clinical assessment of the eye under examination and/or at least one of the following: Test of Break Up Time (TBUT), Schirmer's test, fluorescein staining of the cornea, lissamine green staining, and/or use of subjective DED assessment tools such as the OSDI (Ocular Surface Disease Index) questionnaire. 
7) Reported positive symptoms of DED in study subjects (including, but not limited to, dry eyes, pain, burning, foreign body sensation and photophobia)

Studies were excluded if they:

1) had fully qualitative results.

2) had qualities contrary to those listed in the inclusions above.

\subsection{Data Extraction and Analysis}

Data for each of the included studies were collected using a pre-designed survey form. Data entry and analysis was done using CDC Atlanta's Epi info 7.0 software. Microsoft Word 2007 was used for word processing and the creation of graphs and tables with Microsoft Excel 2007.

The variables studied were:

1) the country of study,

2) Type of study,

3) the number of participants per study,

4) the average age and highest age range of study participants,

5) Frequency of dry eye in the study

6) Risk factors associated with DED,

7) the etiology or diseases underlying the DED,

8) DED diagnostic algorithms and the named treatment of the DED.

\section{Results}

\section{Epidemiology of DED}

1) Prevalence of DED in sub-Saharan Francophone Africa

The recent study conducted in the Democratic Republic of Congo and published in July 2020 [8] found a 90.4\% prevalence of DED in glaucoma patients. The study of BONI S et al. in Côte d'Ivoire in 2018 [5] found a prevalence of $64.16 \%$ of DED in diabetics. Of the 04 studies selected, the average prevalence of DED in French-speaking Sub-Saharan Africa is $53.54 \% \pm 34.60 \%$.

2) Demographic characteristics of the populations studied in French-speaking Sub-Saharan Africa

The average population size for the selected studies [5] [6] [7] [8] was $230 \pm$ 95.90. The average population size for the selected studies [5] [6] [7] [8] was 230 \pm 95.90 . There was an average of 100 males and 130 females, with a sex ratio M/F of 0.76 . The mean age of the series was $57.19 \pm 5.94$ years.

3) Risk factors

The risk factors found were, in descending order:

Old age $=100 \%$ of items.

Female gender $=100 \%$.

Diabetes $=100 \%$.

$\mathrm{HTA}=75 \%$.

Antiglaucoma drugs $=75 \%$.

Extended use of computers $=25 \%$. 
Rheumatoid arthritis $=25 \%$.

Cataract surgery $=25 \%$ and alcohol consumption $=25 \%$.

4) Management of DED in sub-Saharan Francophone Africa

$\checkmark$ Diagnosis of DED in sub-Saharan Francophone Africa

The questionnaires for clinical diagnosis of DED varied from one study to another, BONI S et al. in 2018 [5] had used the international classification of DEWS 2007; Ouffoue G Y et al. in May 2019 [6] had used a pre-established questionnaire with 7 items and finally the OSDI questionnaire was used in July 2020 by Muamba N L et al. [8]. Eballé A.O et al. in January 2019 [7] did not use any questionnaire for clinical diagnosis of DED.

TBUT and Schirmer I DED diagnostic tests were used in $75 \%$ and $50 \%$ of the studies respectively.

The other diagnostic tests for DED were rarely used: MGD (25\%), Schirmer II test (25\%), Fluorescein (25\%) and Lissamine Green (25\%).

$\checkmark$ The therapeutic strategy for DED in sub-Saharan Francophone Africa

None of the 04 studies included any mention of pharmacological and/or non-pharmacological treatment of DED.

\section{Discussion}

\subsection{Limitations of the Study}

Localization bias, notably concerning studies on DED in Subsaharan francophone African countries not yet published.

\subsection{Synthesis of Results}

We carried out a practical synthesis, based on a systematic review of the literature, of the epidemiology and management of DED in French-speaking Sub-Saharan Africa. Our review is based on data extracted from 04 studies conducted by eye health specialists in French-speaking Sub-Saharan Africa (Table 1 ). These studies are based on the prevalence and diagnostic approach of DED in French-speaking Sub-Saharan Africa.

\subsection{Strengths and Limitations of the Review}

For a rigorous scientific approach, we used the recommendations of the PRISMA Statement on systematic reviews. Thus, the process of carrying out this review is clear and transparent. The low number of articles included is one of the limitations of this review. All the articles included are taken from electronic databases. The strengths of our work are the exploitation of 04 search engines and the inclusion of articles published in French or in English, which limits the bias of publication or location and increases the sensitivity of this journal.

\subsection{Results}

The average prevalence of our series above $50 \%$ is significantly higher than the $19.2 \%$ found by the authors in Nigeria in 2014 [9] but lower than the $64 \%$ 
Table 1. Summary of studies included in the systematic review.

\begin{tabular}{|c|c|c|c|c|c|c|}
\hline Authors & Country/City & Number (n) & Mean âge (years) & Mode of diagnostic & Prevalence (\%) & Risk Factor \\
\hline $\begin{array}{l}\text { BONI S. } \\
\text { et al. [5] }\end{array}$ & $\begin{array}{l}\text { Côte d'Ivoire/ } \\
\text { Treichville }\end{array}$ & 240 & 56.39 & $\begin{array}{l}\text { Classification of } \\
\text { DEWS } 2007\end{array}$ & 64.16 & $\begin{array}{c}\text { Old age } \\
\text { Female gender } \\
\text { Diabetes }\end{array}$ \\
\hline $\begin{array}{l}\text { Ouffoue G. Y. } \\
\text { et al. [6] }\end{array}$ & $\begin{array}{l}\text { Côte d'Ivoire/ } \\
\text { Abidjan }\end{array}$ & 234 & 49.1 & $\begin{array}{c}7 \text { items questionnaire, } \\
\text { TBUT }\end{array}$ & 7.5 & $\begin{array}{c}\text { Old age } \\
\text { Femal gender } \\
\text { Ordinateur }\end{array}$ \\
\hline $\begin{array}{c}\text { Eballé A. O. } \\
\text { et al. [7] }\end{array}$ & $\begin{array}{l}\text { Cameroun/ } \\
\text { Douala }\end{array}$ & 340 & 62 & $\begin{array}{l}\text { TBUT, MGD, } \\
\text { Test Schirmer I }\end{array}$ & 52.1 & $\begin{array}{c}\text { Old age } \\
\text { Femal gender } \\
\text { Cataract surgery } \\
\text { HTA } \\
\text { Antiglaucomateux } \\
\text { Consommation d'alcool }\end{array}$ \\
\hline $\begin{array}{l}\text { Muamba N. L. } \\
\text { et al. }[8]\end{array}$ & $\begin{array}{l}\text { R D Congo/ } \\
\text { Kinshasha }\end{array}$ & 106 & 61.3 & $\begin{array}{l}\text { TBUT, Test Schirmer } \\
\text { I et II, Fluoresceine, } \\
\text { Vert de Lissamine, } \\
\text { OSDI }\end{array}$ & 90.4 & $\begin{array}{c}\text { Old age } \\
\text { Femal gender } \\
\text { HTA } \\
\text { Diabetes } \\
\text { Polyarthrite rhumatoïde } \\
\text { Antiglaucomateux }\end{array}$ \\
\hline
\end{tabular}

observed in Palestine in 2018 [10]. Conducting our studies only in at-risk individuals justifies our results and attests to the extent of DED that can be considered as a public health problem.

The female predominance of our review (Sex Ratio $=0.76)$ is in agreement with the Nigerian $($ Sex Ratio $=0.92)[9]$ and Pakistani $($ Sex Ratio $=0.89)$ authors [10]. The demographic arguments support our result.

The mean age of our review was $57.19 \pm 5.94$ is significantly higher than the results found in Nigeria [9] and Pakistan [10], which found mean ages of $50.1 \pm$ 19.06 years and $43.61 \pm 18.57$ years, respectively. DED, the prerogative of the elderly, occurs most often in states of co-morbidity.

As for risk factors, our results are in agreement with the literature on the pathogenesis of DED [11] [12] [13]. Indeed, advanced age is a risk factor for DED due to the qualitative and/or quantitative alteration of tear film synthesis. This abnormality of tear film production may be either primary or secondary to diseases frequently encountered in the elderly (diabetes, rheumatoid arthritis, etc.). The literature [11] [12] [13] has also shown the existence of a significant link between DED and the female sex, particularly after menopause, certainly due to the low levels of sex hormones playing a stimulating role in the activity of the lacrimal glands, Meibomius glands and caliciform cell density. Diabetes is thought to act by disrupting the osmolarity of the tear film secondary to chronic hyperglycemia. The toxicity of the preservatives of anti-glaucomatous eye drops (benzalkonium chloride in particular) for the ocular surface would explain the occurrence of DED in case of prolonged use. 
And for the clinical diagnosis of DED, our review showed that questionnaires were used in $75 \%$ of the articles to study the natural history of the disease and the degree of discomfort caused by the main symptoms of the disease. However, the use of these questionnaires has not been uniform. Several validated questionnaires on DED exist, including: the Ocular Surface Disease Index Questionnaire (OSDI, one of the most widely used diagnostic tools in the world); the McMonnies Questionnaire; the DEQ-5 Questionnaire; the SPEED Questionnaire; and others. It is therefore important for eye health professionals practicing in French-speaking Sub-Saharan Africa to validate a diagnostic questionnaire adapted to the realities of the continent.

Efforts should also be made in the use of other diagnostic tests for DED, which have so far been under-used in Francophone Sub-Saharan Africa.

In addition, the therapeutic strategy for DED in Francophone Sub-Saharan Africa deserves the sustained attention of eye health professionals in order to comply with international standards.

\section{Conclusion}

In Francophone Sub-Saharan Africa, DED affects many more women and people in their quinquagenarians. Its average prevalence is estimated at more than $50 \%$. The diagnostic approach and therapeutic strategy for DED in this part of Africa deserve to be rethought in order to comply with international standards.

\section{Conflicts of Interest}

The authors declare no conflicts of interest regarding the publication of this paper.

\section{References}

[1] Jones, L., Downie, L.E., Korb, D., Benitez-del-Castillo, J.M., Dana, R., et al. (2017) TFOS DEWS II Management and Therapy Report. The Ocular Surface, 15, 575-628. https://doi.org/10.1016/j.jtos.2017.05.006

[2] Tan, L.L., Morgan, P., Cai, Z.Q. and Straughan, R.A. (2015) Prevalence of and Risk Factors for Symptomatic Dry Eye Disease in Singapore. Clinical and Experimental Optometry, 98, 45-53. https://doi.org/10.1111/cxo.12210

[3] Abd Rahman, A., Aljarousha, M., Badarudin, N., Che Azemin, M. and Awad, K. (2018) Prevalence and Risk Factors of Dry Eye Disease in Kuantan, Malaysia. Makara Journal of Health Research, 22, 27-33. https://doi.org/10.7454/msk.v22i1.8749

[4] Osae, A.E., Gehlsen, U., Horstmann, J., Siebelmann, S., Stern, M.E., Kumah, D.B. and Steven, P. (2017) Epidemiology of Dry Eye Disease in Africa: The Sparse Information, Gaps and Opportunities. The Ocular Surface, 15, 159-168. https://doi.org/10.1016/j.jtos.2017.01.001

[5] Boni, S., Gbe, K., Konan, A.J., Ano, A.F., Ouffoue,Y.G., et al. (2018) Sécheresse oculaire chez le patient diabetique: A propos de 240 cas colliges au CHU DE TREICHVILLE. Revue de la Société Ouest Africaine d'Ophtalmologie, No. 1, 7-13 
[6] Ouffoue, G.Y., Boni, S., Ouattara, A.O., Gbe, K., Kouassi, L.J.K., et al. (2019) Contribution du break up time au diagnostic et à la prise en charge du syndrome sec oculaire en milieu tropical: A propos de 234 yeux à Abidjan. Journal Français D’ Ophtalmologie, 42, 716-721. https://doi.org/10.1016/j.jfo.2018.08.017

[7] Eballé, A.O., Ellong, A., Wang, R.E., Mbakop, C.Y., Bella, A.L. and Mvogo, C.E. (2019) Dysfonctionnement des glandes de Meibomius et surface oculaire du sujet âgé mélanoderme. Journal Français D’Ophtalmologie, 42, 127-132. https://doi.org/10.1016/j.jfo.2018.06.008

[8] Muamba, N.L., Dinkulu, M.S., Kelekele, K.J. and Kayembe, L.D. (2020) Fréquence du syndrome sec oculaire et observance chez les patients glaucomateux à Kinshasa. Journal d'Epidemiologie et de Santé Publique, 21, 65-73.

[9] Onwubiko, S.N., Eze, B.I., Udeh, N.N., Arinze, O.C., Onwasigwe, E.N. and Umeh, R.E. (2014) Dry Eye Disease: Prevalence, Distribution and Determinants in a Hospital-Based Population. Contact Lens and Anterior Eye, 37, 157-161. https://doi.org/10.1016/j.clae.2013.09.009

[10] Shanti, Y., Shehada, R., Bakkar, M.M. and Qaddumi, J. (2020) Prevalence and Associated Risk Factors of Dry Eye Disease in 16 Northern West Bank Towns in Palestine: A Cross-Sectional Study. BMC Ophthalmology, 20, Article No. 26. https://doi.org/10.1186/s12886-019-1290-Z

[11] Alzahrani, A., Alhamyani, A., Noor Kalakattawi, R., Noor Kalakattawi, A., Alhamyani, A., Alsuqati, F., et al. (2017) Prevalence of Dry Eye Symptoms and Its Risk Factors among Patients of King Abdulaziz Specialist Hospital (Taif), Saudi Arabia. Saudi Journal for Health Sciences, 6, 140-144. https://doi.org/10.4103/sjhs.sjhs $90 \quad 17$

[12] Alshamrani, A.A., Almousa, A.S., Almulhim, A.A., Alafaleq, A.A., Alosaimi, M.B., Alqahtani, A.M., et al. (2017) Prevalence and Risk Factors of Dry Eye Symptoms in a Saudi Arabian Population. Middle East African Journal of Ophthalmology, 24, 67-73. https://doi.org/10.4103/meajo.MEAJO 281 16

[13] Alharbi, A., Alanazi, N., Alhamad, J., Alabdulqader, R., Aljamea, D., Alabdulqader, S., et al. (2018) Prevalence of Symptomatic Dry Eye and Its Risk Factors among Coastal Population in Eastern Province of Saudi Arabia. Journal of Clinical and Experimental Ophthalmology, 9, 34. https://doi.org/10.4172/2155-9570-C6-094 